\title{
Estudo da degradação da intensidade de fotoluminescência de filmes finos de óxido de alumínio dopados com cério
}

\section{(Time degradation of photoluminescence intensity of cerium doped aluminum oxide thin films)}

\author{
C. C. B. Viana, H. R. Paes Jr. \\ Laboratório de Materiais Avançados - CCT - UENF \\ Av. Alberto Lamego 2000, Horto, Campos dos Goytacazes, RJ 28013-602 \\ viana@uenf.br
}

\begin{abstract}
Resumo
Filmes finos de alumina dopados com cério depositados por spray-pirólise podem ser utilizados como emissores fotoluminescentes na faixa do violeta-azul $(360-410 \mathrm{~nm})$. Todos os espectros destes filmes apresentaram espectros assimétricos resultantes da superposição de dois picos centrados em 365 e $395 \mathrm{~nm}$. Os filmes envelhecidos apresentaram intensidade de luminescência menor que a observada nas amostras como-depositadas. Além disto, foi observado nos espectros das amostras envelhecidas um desvio da banda de emissão para menores comprimentos de onda. $\mathrm{O}$ tratamento térmico a $300^{\circ} \mathrm{C}$ durante oito horas diminuiu a intensidade de luminescência tanto das amostras comodepositadas como envelhecidas. Os filmes tratados apresentaram ainda uma razão entre as áreas dos picos centrados em 365 e $395 \mathrm{~nm}$, menor que a observada nos filmes não-tratados levando ao deslocamento da banda de emissão para maiores comprimentos de onda.
\end{abstract}

Palavras-chave: cério, luminescência, spray-pirólise.

Abstract

Thin films of alumina doped with cerium deposited by spray-pyrolysis can be used as photoluminescent emitters in the range of the violet-blue $(360-410 \mathrm{~nm})$. All of the spectra of these films presented asymmetrical features those are resultants of the overlap of two peaks centered in 365 and $395 \mathrm{~nm}$. The aged films presented smaller luminescence than that observed in the as-deposited samples. Besides, it was observed in the spectra of the aged samples a deviation of the emission band for smaller wavelengths. The thermal treatment at $300^{\circ} \mathrm{Cfor}$ eight hours reduced the luminescence intensity of the as-deposited samples and of the aged samples. The treated films presented a ratio of peak areas centered in 365 and $395 \mathrm{~nm}$ smaller than observed in the non-treated films taking to the displacement of the emission band for larger wavelengths.

Keywords: cerium, luminescence, spray-pyrolysis.

\section{INTRODUÇÃO}

Filmes finos com propriedades fotoluminescentes podem ser aplicados na construção de displays planos luminescentes desde que emitam em uma das três cores básicas para a formação das imagens: azul, verde e vermelho. Além de comprimentos de onda de emissão bem determinados, para a construção de displays planos são requeridas técnicas que permitam a deposição sobre grandes áreas superficiais e que possuam baixo custo de produção. A técnica de deposição por spray-pirólise possui estas características, além de possibilitar a deposição de filmes óxidos com boa uniformidade e transparência [1].

A fotoluminescência é observada em filmes finos de diversos óxidos dopados com terras-raras, como térbio, cério e európio, que emitem nas cores verde, azul e vermelha, respectivamente [2-4]. Em particular, os espectros de filmes óxidos dopados com

Trabalho apresentado no $48^{\circ}$ Congresso Brasileiro de Cerâmica, Curitiba, PR, 2004. cério apresentam bandas largas de característica assimétrica. O comportamento assimétrico das curvas de emissão está relacionado às duas emissões do cério provenientes do decaimento de elétrons do estado mais excitado para os dois estados relaxados muito próximos, ${ }^{2} \mathrm{~F}_{72} \mathrm{e}^{2} \mathrm{~F}_{5 / 2}$. Esta separação no estado relaxado é devida à propriedade dos elétrons exibirem ou spin $+1 / 2$ ou $-1 / 2$ e, portanto, a causa do aspecto assimétrico das curvas é a superposição de duas emissões [5].

Oefeito do tempo sobre aintensidade de emissãoluminescente deve ser avaliado uma vez que, como em muitos dispositivos utilizados em opto e microeletrônica, sob sua ação pode haver uma degradação das propriedades observadas inicialmente. Obviamente, esta degradação não é desejada e existe, portanto, uma preocupação em minimizar este mecanismo.

Assim como o tempo, a variação da concentração de dopante e a influência da temperatura também podem levar a diminuição da intensidade de luminescência. São conhecidos alguns mecanismos que podem ocasionar a diminuição ou o quenching da intensidade de luminescência em terras-raras. 
Um dos principais mecanismos que provocam o quenching da emissão luminescente dos íons de terras-raras é o aumento da concentração de dopante que, diminuindo a distância entre os íons, leva a uma transferência de energia por relaxação cruzada [6]. Um outro mecanismo é denominado de transferência de energia de Förster e Dexter que prediz que a diminuição da intensidade de emissão de um centro luminescente é provocada pela absorção por um outro centro luminescente na mesma faixa de comprimento de onda da emissão do primeiro. Particularmente, quando co-existem dois íons de valências diferentes de uma mesma terra-rara, como $\mathrm{Ce}^{3+} \mathrm{e} \mathrm{Ce}^{4+}$, o primeiro age como emissor e o último como um centro absorvedor de energia na mesma faixa da emissão do $\mathrm{Ce}^{3+}[7,8]$.

Assim sendo, este trabalho teve como objetivos verificar o efeito da concentração de dopante, do tempo decorrido entre a deposição e a medida e dos tratamentos térmicos sobre a luminescência de filmes finos de óxido de alumínio dopados com cério depositados por spray-pirólise. E ainda, através da análise dos resultados, avaliar quais mecanismos atuam sobre a variação da emissão luminescente.

\section{MATERIAIS E MÉTODOS}

As amostras foram preparadas pela técnica de spray-pirólise.
Esta técnica consiste na incidência de um spray - formado por uma solução precursora e um gás de arraste - contendo íons de interesse, sobre substratos dispostos em uma chapa aquecida. No contato do spray com o substrato aquecido uma pirólise ocorre levando a formação de vários compostos, como óxidos e hidróxidos. Para os filmes finos de óxido de alumínio dopados com cério, a temperatura de deposição foi fixada em $300{ }^{\circ} \mathrm{C}$ e lâminas de vidro comum foram utilizadas como substrato. Durante a deposição, o fluxo de ar comprimido foi fixado em $1,5 \mathrm{kgf} / \mathrm{cm}^{2}$ e o fluxo da solução precursora foi mantido em $5 \mathrm{~mL} / \mathrm{min}$. Os filmes foram obtidos a partir da mistura das soluções de cloreto de alumínio hexahidratado $0,1 \mathrm{M}$ diluído em água deionizada e álcool isopropílico (1:3) e cloreto de cério heptahidratado 0,05 M diluído em água deionizada. $\mathrm{O}$ cloreto de cério foi adicionado à solução de cloreto de alumínio nas proporções de 1, 2, 3, 4, 5, 7 e $10 \%$ at..

Para cada concentração de dopante, quatorze amostras foram obtidas numa mesma deposição. Foram estabelecidos cinco intervalos de tempo entre deposição e medida de fotoluminescência: $0,15,30,45$ e 60 dias.

$\mathrm{O}$ tratamento térmico dos filmes foi realizado em uma chapa aquecedora sob atmosfera ambiente na temperatura de $300{ }^{\circ} \mathrm{C}$ durante oito horas. As amostras foram armazenadas em atmosfera ambiente entre os intervalos de medida da luminescência.
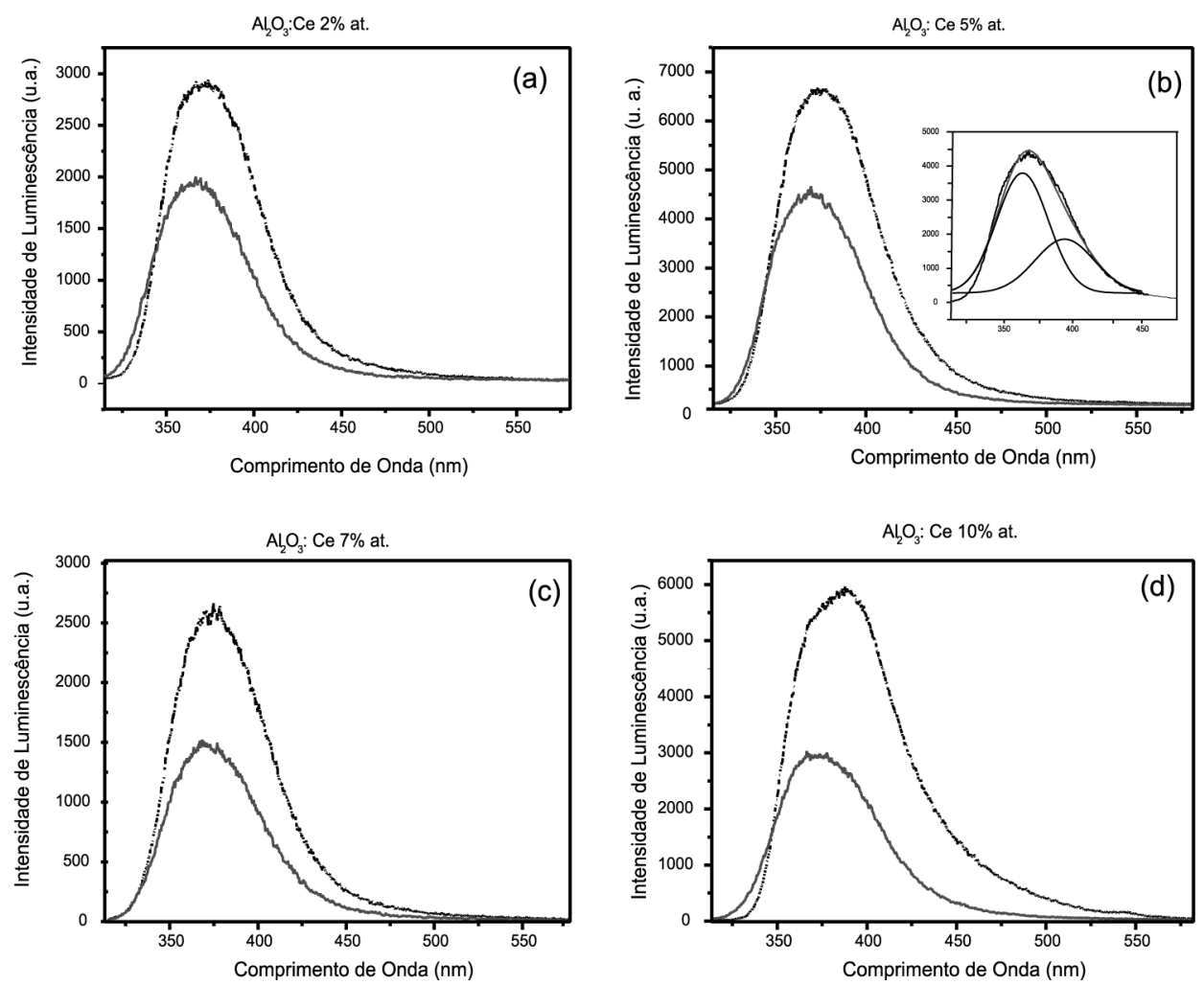

Figura 1: Espectros representativos da fotoluminescência de filmes de óxido de alumínio dopados com (a) 2; (b) 5; (c) 7; (d) 10\% at. de cério como-depositados - cd - (linha tracejada) e envelhecidas por 15 dias - e15 - (linha contínua). No detalhe de (b), a deconvolução em duas gaussianas da amostra 5\% at. envelhecida.

[Figure 1: Representative spectra of the photoluminescence of aluminum oxide films doped with (a) 2; (b) $5 ;$; (c) 7; (d) 10 at.\% of cerium, as-deposited - cd - (dashed line) and aged by 15 days - e15 - (continuous line). In the detail of (b), the deconvolution in two gaussians of the aged sample doped with 5 at.\%] 

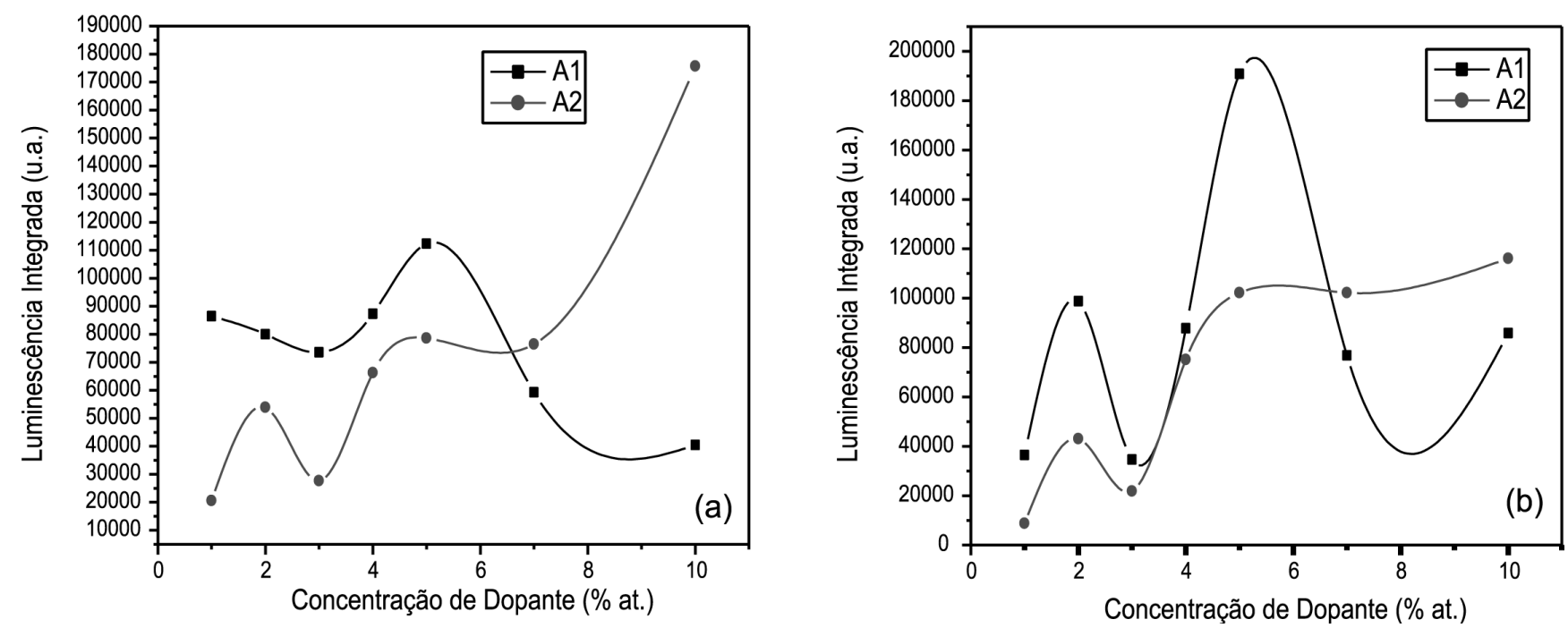

Figura 2: Área sob os picos centrados em 365 (A1) e 395 nm (A2) para amostras (a) como-depositadas e (b) envelhecidas por 15 dias em função da concentração de dopante.

[Figure 2: Area under the peaks centered at 365 (A1) and $395 \mathrm{~nm}$ (A2) to (a) as deposited and (b) aged by 15 days samples.]

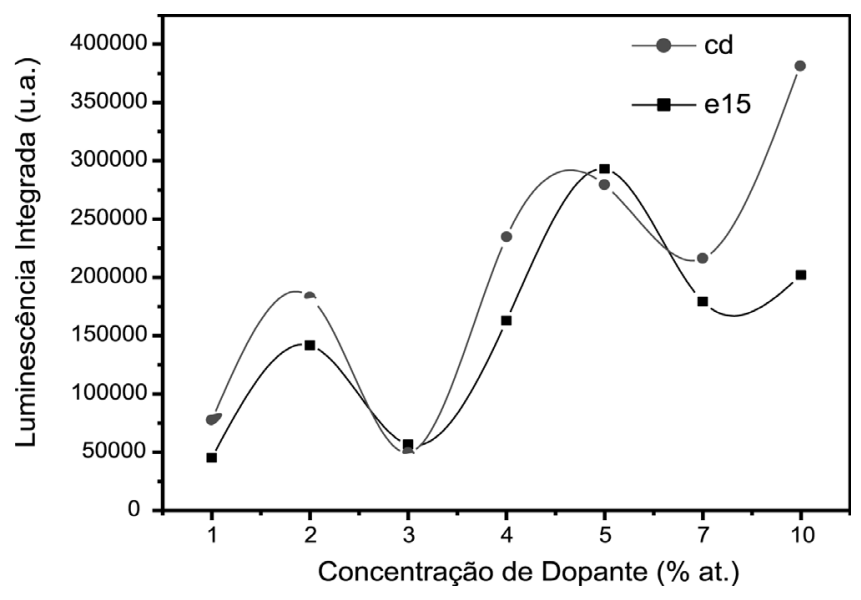

Figura 3: Soma das áreas A1 e A2 em função da concentração de dopante para amostras como-depositadas (cd) e envelhecidas por 15 dias (e15).

[Figure 3: Sum of areas A1 and A2 as a function of the doping concentration to as-deposited (cd) and aged by 15 days (e15) samples.]

As medidas da fotoluminescência foram realizadas em um espectrofluorímetro F-4500 Hitachi utilizando comprimento de onda de excitação fixado em $300 \mathrm{~nm}$.

Em todos os espectros foi realizada uma deconvolução em duas gaussianas, cujos comprimentos de onda centrais foram fixados em 365 e $395 \mathrm{~nm}$, correspondendo às emissões do nível excitado $5 \mathrm{~d}$ para os níveis ${ }^{2} \mathrm{~F}_{7 / 2} \mathrm{e}^{2} \mathrm{~F}_{5 / 2}$, respectivamente. Utilizando este método e através da determinação das áreas sob as gaussianas foi possível determinar, separadamente, a importância de cada uma das duas emissões do cério para as variações da intensidade decorrentes do aumento da concentração de dopante, do envelhecimento e do tratamento térmico.

\section{RESULTADOS E DISCUSSÃO}

As Figs. 1 (a) - (d) apresentam os espectros de emissão de amostras de óxido de alumínio dopadas com 2, 5, 7 e $10 \%$ at. de cério como-depositadas e envelhecidas por 15 dias. Observa-se que nas amostras medidas após 15 dias de deposição ocorreu um pequeno desvio das bandas de emissão para menores comprimentos de onda além da diminuição da intensidade dos picos. No detalhe da Fig. 1 (b), pode ser observada uma deconvolução em duas gaussianas para a amostra dopada com 5\% at. de Ce envelhecida por 15 dias.

Na Fig. 2 é apresentada a variação das áreas sob as gaussianas obtidas dos espectros de amostras como-depositadas e envelhecidas por 15 dias em função da concentração de cério. Considerando-se, A1 e A2 as áreas sobre as gaussianas centradas em 365 e $395 \mathrm{~nm}$, respectivamente, observa-se que as áreas sobre os picos centrados em $365 \mathrm{~nm}$ (A1) são maiores que as áreas sobre os picos centrados em $395 \mathrm{~nm}$ para filmes dopados com concentrações de até 5\% at. de cério tanto para amostras comodepositadas como para amostras envelhecidas, Fig. 2(a) e 2(b), respectivamente. Este comportamento é alterado para maiores concentrações de dopante tanto nas amostras como-depositadas (Fig. 2(a)) como nas amostras envelhecidas (Fig. 2 (b)).

Como é observado nas Fig. 2 (a) e 2(b), para as concentrações de 7 e $10 \%$ at. de cério, as áreas sobre os picos centrados em 395 nm são predominantes, sendo que nas amostras como-depositadas a relação A2/A1 é bem maior que a observada nas amostras envelhecidas. Analisando a Fig. 3, onde é apresentado o gráfico da soma das áreas A1 e A2 para as amostras como-depositadas e envelhecidas, pode ser verificado que na luminescência das amostras comodepositadas existe uma tendência ao aumento da intensidade com aumento da concentração de dopante para amostras com até $5 \%$ at. de cério. Para concentrações maiores que 5\% at. de cério, observa-se uma tendência à saturação da intensidade. 
Isto indica que de um modo geral, o comportamento da emissão dos filmes como-depositados é determinado pelo pico de emissão centrado em $365 \mathrm{~nm}$, haja vista a queda dos valores da área 1 para amostras com concentração maior que 5\% at..

No caso dos filmes como-depositados, a emissão em $365 \mathrm{~nm}$, correspondente a transição $5 \mathrm{~d} \rightarrow{ }^{2} \mathrm{~F}_{5 / 2}$, pode estar sendo saturada pela concentração de dopante, no mecanismo denominado quenching ou, mais apropriadamente, o self-quenching da concentração [6]. Este mecanismo atua, sobretudo, no subnível mais externo ${ }^{2} \mathrm{~F}_{7 / 2}$ porque possivelmente deva estar ocorrendo uma transferência de energia para este subnível de outros íons de cério próximos. Um esquema baseado no mecanismo de quenching entre subníveis de íons cério próximos pode ser observado na Fig. 4.

Ainda na Fig. 3, para as amostras envelhecidas por 15 dias, observa-se que a intensidade de luminescência aumenta com a concentração de cério até $5 \%$ at., comportamento semelhante ao observado para amostras como-depositadas. Entretanto, nas

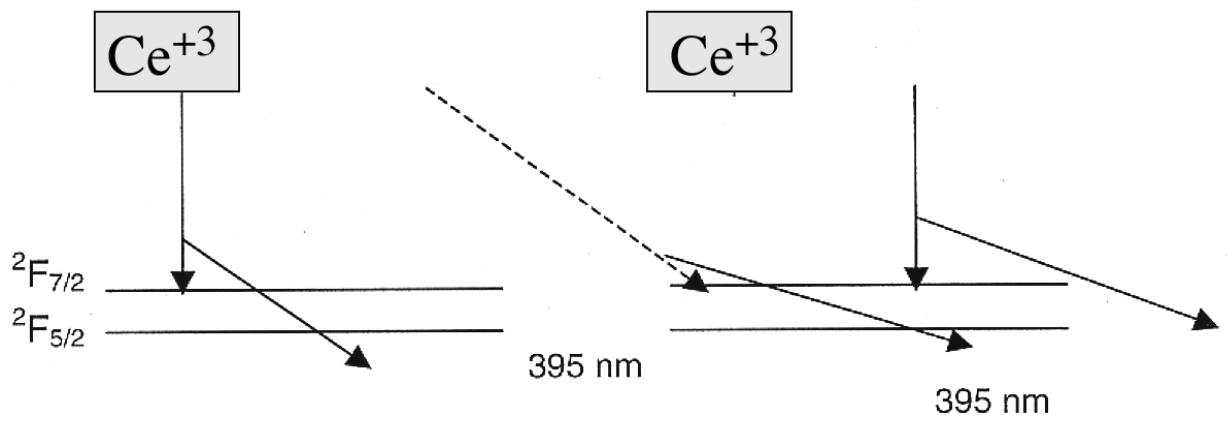

$395 \mathrm{nn}$

Figura 4: Diagrama esquemático do mecanismo de quenching por relaxação cruzada entre subníveis de íons Ce $^{3+}$ vizinhos. [Figure 4: Scheme of the quenching mechanism by cross relaxation among Ce ${ }^{3+}$ neighbors.]
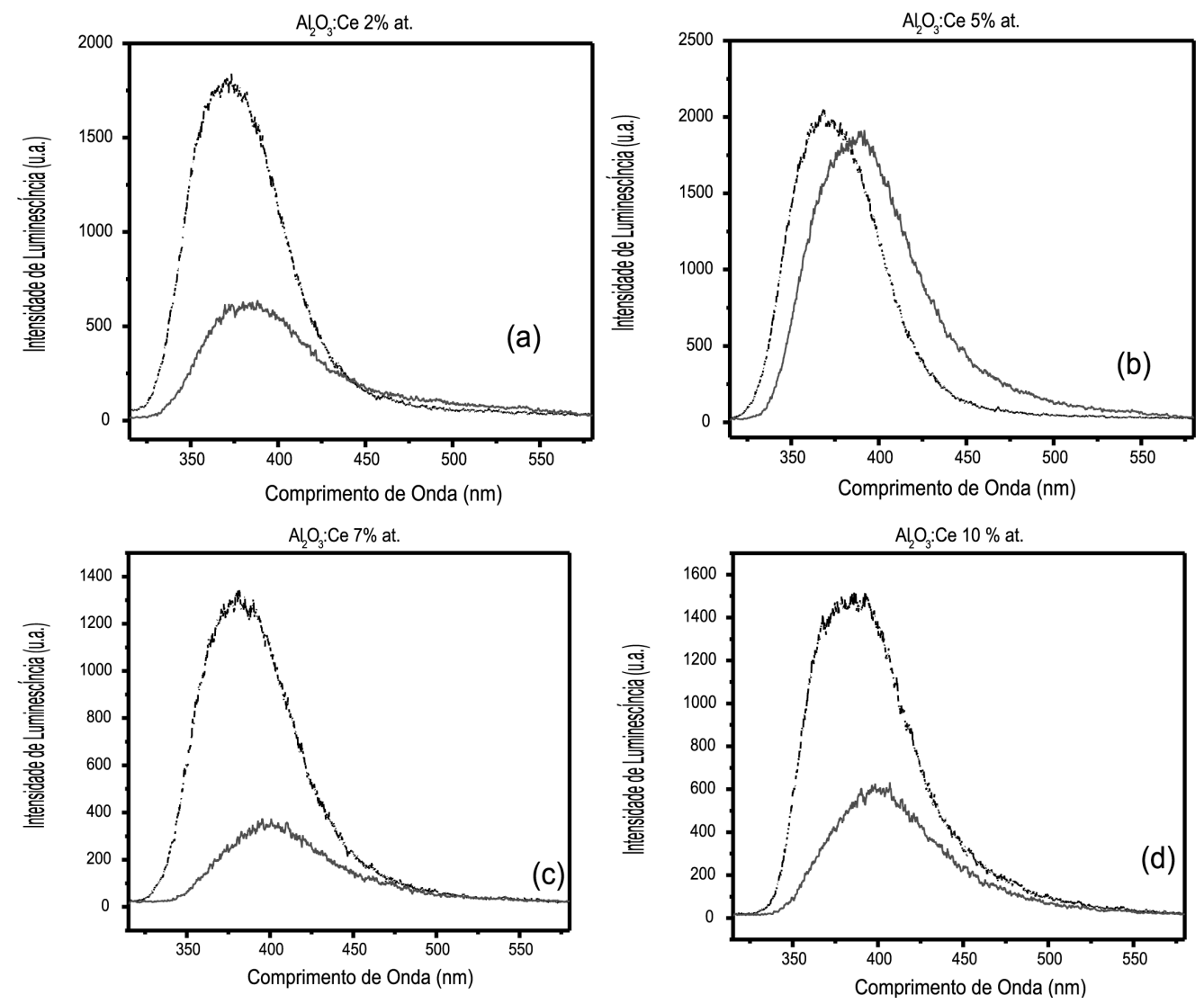

Figura 5: Espectros representativos da fotoluminescência das mostras como-depositadas de óxido de alumínio dopadas com cério em (a) 2 , (b) 5, (c) 7 (d) $10 \%$ at., antes (linha tracejada) e após (linha contínua) tratamento térmico.

[Figure 5: Representative spectra of the photoluminescence of the as-deposited samples of aluminum oxide doped with cerium in (a) 2, (b) 5, (c) 7 (d) 10 at.\%., before (dashed line) and after (continuous line) thermal treatment.] 
amostras envelhecidas com concentrações maiores que $5 \%$ at. a intensidade diminui mais significantemente. De fato, analisando o comportamento individual das áreas A1 e A2 (Fig. 2) para as amostras envelhecidas, observa-se que a área 2 não aumenta com a adição de dopante em concentração maior que $5 \%$ at.. Isto pode indicar que, ao contrário do que ocorre com as amostras comodepositadas, as transições para os subníveis ${ }^{2} \mathrm{~F}_{7 / 2}$ não estejam sendo favorecidas, isto é, a relaxação cruzada não está ocorrendo. Com o envelhecimento, realizado em atmosfera ambiente, ocorre uma perda de cloreto de cério, haja vista a diminuição da intensidade de luminescência observada em todas as amostras envelhecidas. Entretanto, o cloreto remanescente por apresentar natureza higroscópica pode se associar a moléculas de água ou a grupamentos $\mathrm{OH}^{-}$. Esta incorporação ao redor dos íons de cério, dificultaria a aproximação entre eles e, portanto diminuiria o efeito do quenching da concentração por relaxação cruzada.

Para amostras medidas em 30, 45 e 60 dias após a deposição o comportamento dos picos de emissão praticamente mantevese inalterado com relação a desvios e intensidade dos espectros das amostras medidas após 15 dias.

Para todas as amostras analisadas pode ser observado que o tratamento diminui a intensidade de luminescência das amostras e leva as bandas de emissão para maiores comprimentos de onda, isto é, aumenta a razão A2/A1. O efeito do tratamento térmico nas amostras como-depositadas pode ser observado na Fig. 5 (a)-(d) onde são apresentados os espectros de luminescência de filmes finos de óxido de alumínio dopados com 2, 5, 7 e 10\% at. de cério antes e depois do tratamento térmico. Os espectros de luminescência das amostras envelhecidas antes e depois do tratamento térmico são apresentados na Fig. 6 (a)-(d).

Neste caso, a diminuição da intensidade está fortemente relacionada a grande perda do cloro provocada pelo tratamento térmico como pode ser detectado por fluorescência de raios $\mathrm{X}$ [9]. Por outro lado, deve-se observar que houve um aumento da razão A2/A1 e neste caso, o favorecimento do pico em $395 \mathrm{~nm}$ não deve ser atribuído ao self-quenching, mas sim ao mecanismo de transferência de energia predito por Förster e Dexter [7, 8]. Baseado neste mecanismo e de acordo com [8], no presente caso, para íons $\mathrm{Ce}^{3+}$ e $\mathrm{Ce}^{4+}$ coexistindo numa mesma amostra, a emissão do $\mathrm{Ce}^{3+}$ é parcialmente absorvida pelo íon $\mathrm{Ce}^{4+}$.

$\mathrm{Na}$ Fig. 7 observam-se os gráficos da razão A2/A1 para amostras como-depositadas (Fig. 7(a)) e envelhecidas (Fig. 7(b)) após tratamento térmico em função da concentração de dopante. Observa-se que após o tratamento térmico, a razão A2/A1 para concentrações de até $5 \%$ at. de cério é praticamente constante tanto nas amostras como-depositados como nas amostras envelhecidas. Para concentrações maiores que 5\% at., a razão aumenta consideravelmente, indicando que as emissões em 395
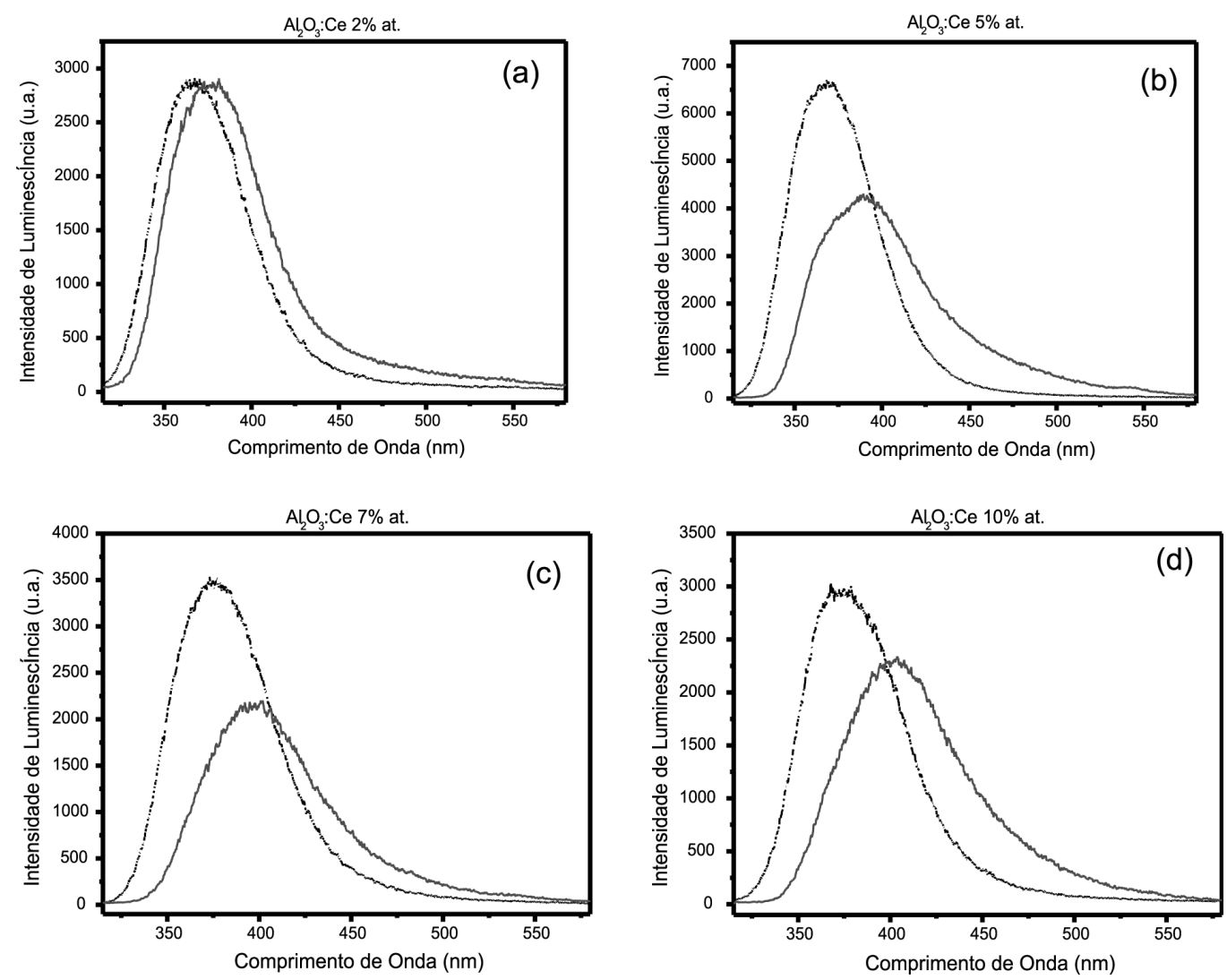

Figura 6: Efeito do tratamento térmico sobre os espectros de fotoluminescência de amostras envelhecidas de filmes finos de óxido de alumínio dopadas com cério em (a) 2, (b) 5, (c) 7 (d) 10\% at., antes (linha tracejada) e após (linha contínua) tratamento. [Figure 6: Effect of the thermal treatment in aged samples of aluminum oxide doped with cerium in (a) 2, (b) 5, (c) 7 (d) 10 at.\%, before (dashed line) and after (continuous line) thermal treatment.] 

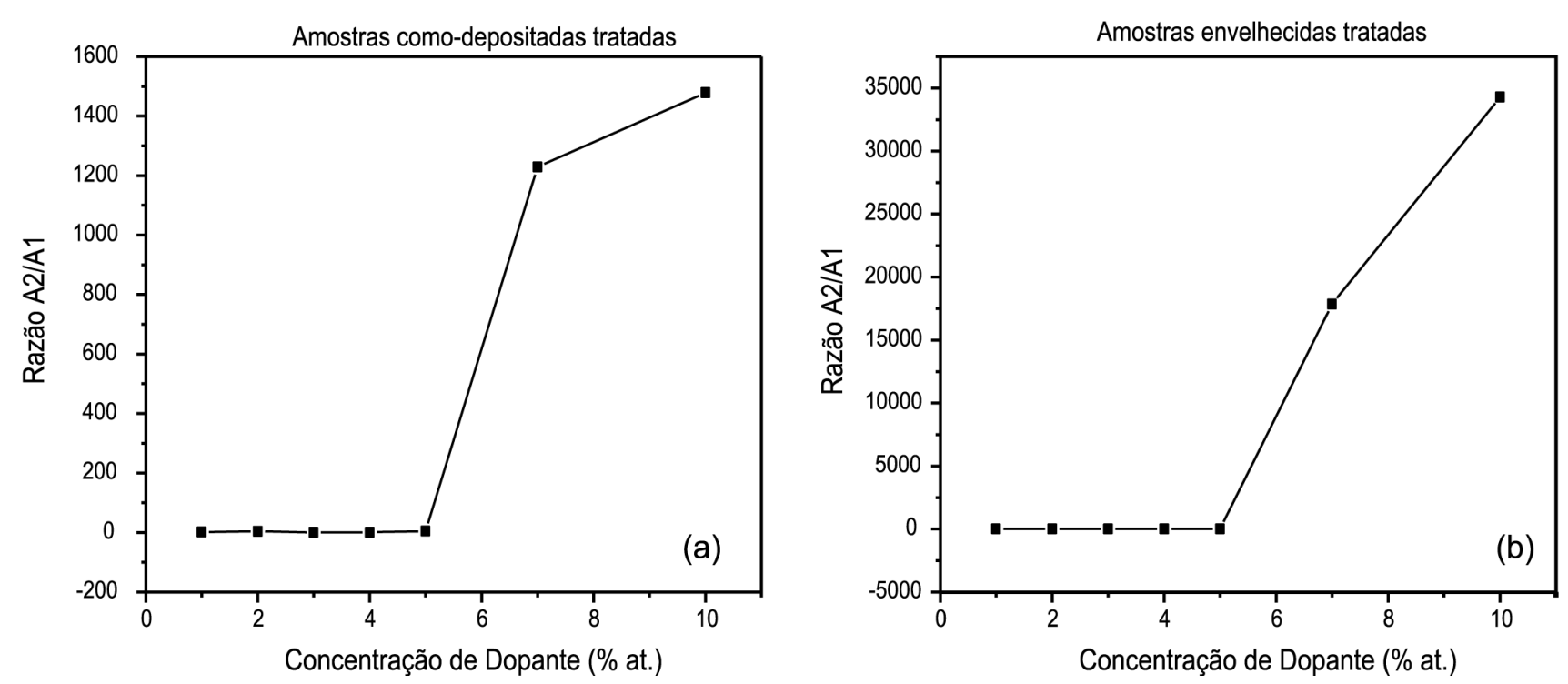

Figura 7: Razão das áreas das gaussianas centradas em 395 nm pelas áreas das gaussianas centradas em 365 nm (A2/A1) em função da concentração de dopante para amostras (a) como-depositadas após tratamento térmico e (b) envelhecidas após tratamento térmico.

[Figure 7: Ratio of the areas of the gaussians centered in $395 \mathrm{~nm}$ to the areas of the gaussians centered in $365 \mathrm{~nm}$ (A2/A1) as function of the doping concentration to (a) as-deposited after thermal treatment and (b) aged after thermal treatment samples.]

nm são predominantes nestas amostras. Neste caso, a presença do íon $\mathrm{Ce}^{4+}$ também poderia explicar o quenching observado para concentrações maiores que 5\% at.. Admitindo que a partir de $5 \%$ at. a concentração de $\mathrm{Ce}^{3+}$ seja mantida constante, mesmo com aumento da concentração de dopante no filme, os íons que excedessem a uma concentração crítica seriam oxidados mais facilmente, ou seja, convertidos para $\mathrm{Ce}^{4+}$, e atuaria portanto como um centro absorvedor nestas amostras.

\section{CONCLUSÕES}

Os filmes de óxido de alumínio dopados com cério apresentaram uma larga banda de emissão fotoluminescente. Para todas as amostras, os espectros apresentaram aspecto assimétrico proveniente do desdobramento (splitting) do estado $4 \mathrm{f}$ do cério, que determina a emissão em dois comprimentos de onda, 365 e $395 \mathrm{~nm}$. As faixas de comprimento de onda das bandas de emissão, tal como a intensidade de luminescência, apresentaram variação com respeito à concentração de dopante, tempo de envelhecimento e tratamento térmico.

Nas amostras como-depositadas, a intensidade de luminescência aumentou com a concentração de cério até $5 \%$ at.. Para concentrações maiores que 5\% at. de cério, este aumento mostrou ser influenciado pela emissão centrada em $395 \mathrm{~nm}$, que se torna predominante devido ao quenching da concentração por relaxação cruzada.

O envelhecimento das amostras levou a diminuição da intensidade de luminescência associada à perda de cloro e ainda, provocou um deslocamento das bandas de emissão para menores comprimentos de onda possivelmente devido à presença de grupamentos, como o $\mathrm{OH}^{-}$, ao redor do íon cério.

$\mathrm{O}$ tratamento térmico diminuiu ainda mais a intensidade dos espectros além de deslocar os espectros para maiores comprimentos de onda. Este comportamento parece estar associado à absorção da energia de emissão dos centros de $\mathrm{Ce}^{3+}$ por centros de $\mathrm{Ce}^{4+}$ conforme é predito pelo mecanismo de transferência de energia de Förster e Dexter.

\section{AGRADECIMENTOS}

Os autores agradecem a FAPERJ pelo apoio financeiro.

\section{REFERÊNCIAS}

[1] A. E. Esparza-García, M. García-Hipólito, M. A. Frutis, C. Falcony, J. Electrochem. Soc. 150, 2 (2003) 2160.

[2] K. D. Oskam, K. A. Kaspers, A. Meijerink, H. MüllerBunz, Th. Schleid, J. Lum. 99 (2002) 105.

[3] T. Ishizaka, R. Nozaki, Y. Kurokawa, J. Phys. Chem. Sol. 63 (2002) 613.

[4] C. Falcony, M. García, A. Ortiz, O. Miranda, I. Gradilla, G. Soto, L. Cota-Araiza, M. H. Farias, J. C. Alonso, J. Electrochem. Soc. 241, 1 (1994) 2860.

[5] B. Hüttl, U. Troppenz, K. O. Velthaus, C. R. Ronda, R. H. Mauch, J. Appl. Phys. 78, 12 (1995) 7282.

[6] G. Blasse, in Luminescence of Inorganic Solids (Ed. B. Bartolo), Plenum Press, New York and London (1967) 247.

[7] J. Hao, Z. Lou, M. Cocivera, Appl. Phys. Lett. 82, 9 (2003) 1404.

[8] G. Özen, B. Demiderata, Spectrochim. Acta Part A 5, 6 (2000) 1795.

[9] C. C. B. Viana, Caracterização estrutural e ótica de filmes finos de alumina dopados com cério depositados por spraypirólise, Dissertação de Mestrado em Engenharia e Ciência dos Materiais, Laboratório de Materiais Avançados, UENF (2001). (Rec. 28/06/2004, Ac. 24/09/2004) 